\title{
Cálcio e Fósforo no Leite da Região de Piracicaba (*)
}

H. Petrin Junior

Terceiranista da E. S. A. \&L. Q.»
R. A. Catani

E. S. A. «Luiz de Queiroz»

H. Rergamin Filho - E. S. A. \&Luiz de Queiroz»

(*) Recebido para publicaçăo em 28/10/1960. 


\section{INTRODUÇÃO}

- O leite é um alimento de grande importância ao homem. Há muito que o leite é conhecido como alimento rico em cálcio e fósforo, quando comparado aos demais produtos, empregados na dieta humana. A importância do leite, como supridor de cálcio e fósforo mais se acentúa, quando ć considerada a alimentação da criança nos primeiros anos de vida e a sua necessidade nos citados elementos.

O objetivo do presente trabalho foi o de sc conhecer os teores de cálcio e fósforo no leite distribuido à população de Piracicaba.

\section{MATERIAL E METODOS}

\subsection{Material.}

O material constou de leite distribuido para consumo domiciliar pela organização Lacticinios Piracicaba Limitada, cuja Usina recebe 12.000 litros por dia, sendo $10 \%$ fornecidos por Piracicaba e o restante pelas regiões circunvizinhas. (1).

$O$ leite recebido na Usina é totalmente misturado, antes de ser submetido à pasteurização, de modo que não há possibilidade de variação em sua composição, devida a sua origem.

As amostras de $100 \mathrm{ml}$ de leite, em número de 12 , foram retiradas no período compreendido entre 25 de março e 7 de agôsto de 1959. Os $100 \mathrm{ml}$ foram retirados de 1 litro de leite distribuido para diversos consumidores, pela Lacticínios Piracicaba Limitada, depois de homogeneizado.

Os $100 \mathrm{ml}$ de leite, depois de transferidos para vidros limpos e secos foram levados ao laboratório para serem analisados.

\subsection{Métodos.}

\section{a) Preparo da amostra}

Foram transferidos $5 \mathrm{ml}$ de leite para uma cápsula de porcelana e deixou-se secar em banho-maria. Colocou-se a cápsula em estufa, à $110^{\circ} \mathrm{C}$, deixou-se durante uma hora, e depois do material secar completamente, incinerou-se à $550-600^{\circ} \mathrm{C}$, durante 10 a 15 minutos. Foram adicionados $5 \mathrm{ml}$ de $\mathrm{HCl}(1+1)$, aqueceu-se em banho-maria e filtrou-se para balão de $50 \mathrm{ml}$, através de papel

(1) Informações verbais colhidas na firma pausterizadora... 
SS 589, faixa branca. Lavou-se com água destilada, esperou-se esfriar c completou-se o volume (solução origninal).

\section{b) Determinação do cálcio}

Foram transferidos, por meio de pipeta, $25 \mathrm{ml}$ da solução original, para um copo de $250 \mathrm{ml}$. Foram adicionados 25 a $30 \mathrm{ml}$ de água destilada, 5 a 6 gotas de solução de vermelho de metilo e aqueceu-se à ebulição. Em seguida, foram acrescentados $10 \mathrm{ml}$ de solução saturada de oxalato de amônio e $\mathrm{NH}_{4} \mathrm{OH}$ até a viragem do indicador. O precipitado de oxalato de cálcio formado foi filtrado, lavado, dissolvido em solução de $\mathrm{H}_{2} \mathrm{SO}_{1}$ e a determinação do cálcio se processou de acôrdo com o método clássico baseado no emprêgo de solução de $\mathrm{KMnO}_{1}$, que no presente caso foi 0,02 normal.

\section{c) Determinciợco do fósforo}

Foram transferidos $2 \mathrm{ml}$ da solução original, por meio de pipeta, para um balão de Erlenemeyer de $50 \mathrm{ml}$. Foram adicionados $8 \mathrm{ml}$ de solução de $\mathrm{HCl} 0,6$ normal, $7 \mathrm{ml}$ de água destilada, $2 \mathrm{ml}$ de solução de metavanadato de amônio a $0,25 \%$ e $1 \mathrm{ml}$ de solução de molibdato de amônio a $10 \%$. Depois de 15 minutos, procedeu-se a leitura da transmissão porcentual da luz, em colorimetro fotoelétrico Beckman, modêlo C, empregando-se filtro azul, 440 milinicrons. Obtida a densidade ótica da solução, a mesma foi convertida em concentração de fósforo, mediante uma curva prèviamente construida, que relacionava densidade ótica e conceniração de fósforo de soluções padrões.

\section{3 - DADOS OBTIDOS E DISCUSSÃO}

Os dados obtidos estão condensados no Quadro I

$\mathrm{Na}$ 1.a e 2.a colunas do Quadro I são apresentados o número da amostra e a data de sua coleta, respectivamente. $\quad \mathrm{Na}$ 3.a e 4.a colunas, o número de $\mathrm{mg}$ de cálcio, Ca, e o n. ${ }^{\mathrm{e}}$ de $\mathrm{mg}$ de fósforo, $P$, respectivamente, determinados em $100 \mathrm{ml}$ de leite.

O que chama a atenção em primeiro lugar, é a constância relativa dos resultados, quer quanto ao cálcio, como em relação ao fósforo. O cálcio variou de 119 a $136 \mathrm{mg}$ de $\mathrm{Ca}$, e o fósforo de 83 a $91 \mathrm{mg}$ de $\mathrm{P}$, por $100 \mathrm{ml}$ de leite. Quando se considera que as variações indicadas refletem as diferentes partidas de leite, amostragem e outros fatôres, pode-se admitir que as citadas flutuações não foram intensas. 
QUADRO I

Conccntração de cálcio e fósforo no leite da região cle Piracicaba.

Dados $\mathrm{cm} \mathrm{mg} \mathrm{de} \mathrm{cálcio} \mathrm{e} \mathrm{mg}$ de fósforo, por $100 \mathrm{ml}$ de leite.

\begin{tabular}{|c|c|c|c|}
\hline \multirow{2}{*}{$\begin{array}{l}\text { N.o da } \\
\text { Amostra }\end{array}$} & \multirow{2}{*}{ DATA } & \multicolumn{2}{|c|}{$\mathrm{mg}$ por $100 \mathrm{ml}$ de leite } \\
\hline & & CÁLCIO & FOSFORO \\
\hline 1 & $25 / 3 / 59$ & 135 & 91 \\
\hline 2 & $2 / 4 / 59$ & $\begin{array}{l}132 \\
131 \\
133\end{array}$ & $\begin{array}{l}91 \\
83 \\
91\end{array}$ \\
\hline 3 & $14 / 4 / 59$ & $\begin{array}{l}134 \\
135 \\
134\end{array}$ & $\begin{array}{l}91 \\
91 \\
91\end{array}$ \\
\hline 4 & $27 / 4 / 59$ & $\begin{array}{l}136 \\
135 \\
13.5\end{array}$ & $\begin{array}{r}91 \\
91 \\
100\end{array}$ \\
\hline 5 & $4 / 5 / 59$ & $\begin{array}{l}129 \\
129 \\
131\end{array}$ & $\begin{array}{l}91 \\
91 \\
91\end{array}$ \\
\hline 6 & $19 / 5 / 59$ & $\begin{array}{l}131 \\
126 \\
128\end{array}$ & $\begin{array}{l}91 \\
91 \\
91\end{array}$ \\
\hline 7 & $25 / 5 / 59$ & $\begin{array}{l}133 \\
135 \\
135\end{array}$ & $\begin{array}{l}91 \\
91 \\
91\end{array}$ \\
\hline 8 & $17 / 7 / 59$ & $\begin{array}{l}124 \\
123 \\
123\end{array}$ & $\begin{array}{l}91 \\
91 \\
91\end{array}$ \\
\hline 9 & $20 / 7 / 59$ & $\begin{array}{l}123 \\
123 \\
121\end{array}$ & $\begin{array}{l}91 \\
91 \\
91\end{array}$ \\
\hline 10 & $24 / 7 / 59$ & $\begin{array}{l}132 \\
132\end{array}$ & $\begin{array}{l}91 \\
91 \\
91\end{array}$ \\
\hline 11 & $30 / 7 / 59$ & $\begin{array}{l}120 \\
120 \\
119\end{array}$ & $\begin{array}{l}91 \\
91 \\
91\end{array}$ \\
\hline 12 & $7 / 8 / 59$ & $\begin{array}{l}131 \\
133 \\
133\end{array}$ & $\begin{array}{l}91 \\
91 \\
91\end{array}$ \\
\hline
\end{tabular}


Os dados obtidos para os teores de cálcio e fósforo vêm confirmar que o leite é realmente rico nos elementos em questão.

Comparando-se os resultados obtidos no presente trabalho com os de outros autores, chega-se a conclusão de que os teores de cálcio e fósforo não variam muito.

Assim, conforme cita ROSSEL \& SANTOS (1952), o Instituto Técnico Lactológico de Zurich dá os seguintes valores médios:

Cálcio : $120 \mathrm{mg}$ em $100 \mathrm{~g}$ de leite.

Fósforo: $95 \mathrm{mg}$ em $100 \mathrm{~g}$ de leite.

RONDONI (1935) cita que o leite procedente de 30 cooperativas forneceu os seguintes dados:

Cálcio : $119 \mathrm{mg}$ em $100 \mathrm{~g}$ de leite.

Fósforo : $94 \mathrm{mg}$ em $100 \mathrm{~g}$ de leite.

BISHOV, HENRICK \& MITCHELL, JR. (1959), indicam os seguintes teores :

Cálcio : $112,5 \mathrm{mg}$ em $100 \mathrm{ml}$ de leite.

Fósforo: $85,6 \mathrm{mg}$ em $100 \mathrm{ml}$ de leite. dados :

HAWK, OSER \& SUMMERSON (1954) dão os seguintes

Cálcio: em torno de $130 \mathrm{mg}$ em $100 \mathrm{ml}$.

Fósforo: em torno de $100 \mathrm{mg}$ em $100 \mathrm{ml}$.

E interessante assinalar que os dados relativos ao cálcio e fósforo para o leite da região de Piracicaba apresenta valores muito próximos ao de outras regiões, apesar das diferenças de solos, clima, raças, etc. .

\section{RESUMO E CONCLUSÕES}

O presente trabalho relata os dados obtidos na determinação do cálcio e do fósforo em 12 amostras de leite distribuido pela Lecaticinios Piracicaba Limitada, para consumo da população.

As conclusões obtidas foram as seguintes :

As 12 amostras, que abrangeram o período compreendido entre 25 de março e 7 de agôsto de 1959, apresentaram pequena variação na concentração de cálcio e fósforo em $100 \mathrm{ml}$ de leite. Assim o cálcio variou de 119 a $136 \mathrm{mg}$ de $\mathrm{Ca}$ e o fósforo de 83 a $91 \mathrm{mg}$ de $P$, por $100 \mathrm{ml}$ de leite Quando se consideram os diferentes fatôres que podem afetar a variação da concentração de ele- 
mentos no leite, conclui-se que realmente, as oscilações observadas não foram pronunciadas.

Comparando-se os dados obtidos com os de outros paises, verifica-se que, apesar das diferenças de clima, solo, alimentação e mesmo raças leiteiras, infere-se que o teor em cálcio e fósforo do leite de vaca é relativamente invariável.

\section{SUMMARY}

Twelve samples of fluid milk delivered by "Laticinios Piracicaba Ltda." for public consumption, from March 25 do August 7, 1959, were analysed to determine its calcium and phosphorus content per $100 \mathrm{ml}$. A slight variation was observed. Calcium varied from 119 to $136 \mathrm{mg}$ and phosphorus from 83 to $91 \mathrm{mg}$. These results are comparable to the ones obtained in other countries, showing that calcium and phosphorus content in cow milk is almost invariable.

\section{BIBLIOGRAFIA}

BISHOV, S. J., A. S. HENICK \& J. H. MITCHELI., JR. - 1959. Ratc of mineral removal from milk by ion cxchange. Foced Rescarch, 24:428-43.3.

H.HK, P. B.. H. L. OSER \& W. S. SLM MERSON - 19.34. Practical Physiological Chemistry. pl. 219-241. 13th edition. The Blakiston Company Inc. New York.

RONDON1, P. - 1935. Compendio de Bioquinica, pp. 293-301 4.a ediçăo espanhola traduzidla da 3.a edição italiana. Folitorial Labor. Barcelona.

ROSSEL. J. \& I SANOOS - 19.52. Métodos analitions de laboratório lactológicon, Tomo 1, pp. 913. Eelit. Iabor. 